\title{
ARChIVOS DE CONOCIMIENTO Y LA CULTURA LEgal DE LA PUBLICIDAD EN LA MARSELLA MEDIEVAL '
}

\author{
por
}

DANIEL LORD SMAIL

Fordham University. New York.

RESUMEN: Este artículo, basado en un estudio de casos de Marsella en el siglo XIV, argumenta que la publicidad fue, incluso en el mundo de la baja Edad Media cuando parecen dominar las normas escritas del Derecho Romano, una metáfora fundamental de la cultura legal medieval. Al comportarse de una forma abierta y pública, hombres y mujeres conseguían inscribir información de hechos legales básicos, tales como edad, parentesco, derechos, estatus marital, y fecha de fallecimiento, en los archivos públicos de la memoria, en un periodo anterior al momento en que tales datos fueron sistemáticamente registrados por escrito en los archivos. La naturaleza abierta y ceremonial de tal comportamiento validaba y otorgaba autoridad a la información creada de ese modo. Debido a esto, en casos judiciales los litigantes intentaban mostrar no sólo que ciertos hechos favorecían su posición, sino también que los mismos eran de «voz y conocimiento público». Para hacerlo, frecuentemente reclutaban testigos de un espectro social amplio, y la composición del grupo de testigos servía para ilustrar la amplitud lograda por esos actos. Según este argumento, el cambio más profundo en la cuitura legal europea no tuvo lugar con la transformación del derecho oral y consuetudinario al derecho escrito, sino con una transformación posterior, la de los archivos de conocimiento públicos y facilmente accesibles, a los cada vez más privados y de control estatal de la época modema.

Palabras clave. Cultura legal. Marsella. Publicidad en derecho. Formas de archivar. Comunicación.

ABSTRACT: Based on a case study of Marseille in the fourteenth century, this article argues that a foundational metaphor of medieval legal culture was publicity, even in the late medieval world where the written norms of Roman law

\footnotetext{
1 Deseo agradecer a Isabel Alfonso, Thelma Fenster y Thomas Kuehn sus útiles consejos y criticas.

Hispania, LVII/3, núm. 197 (1997) 1049-1077
} 
would seem to dominate. In behaving in an open and public way, men and women managed to inscribe knowledge of basic legal facts, such as age, parentage, title, marital status, and date of death, in the public archives of memory, in an age before written archives consistently recorded such basic facts. The openness and ceremonial nature of such behavior validated and lent authority to the knowledge thereby created. In count cases, as a result, litigants sought to show not only that certain facts favored their position, but also that the facts were part of the "public voice and knowledge». To do so, they recruited witnesses from a broad social spectrum, and the composition of the witness group served to illustrate how widely spread the relevant facts were. According to this argument, the most profound change in European legal culture took place not with the shift from oral and customary law to written law, but with a later shift from easily accessible and public archives of knowledge to the incresingly private, state-controlled archives of the early modern era.

KEY words: Legal. culture. Marseille. Publicity in law. Memory. Archival forms. Communication.

En toda sociedad las personas tienden a disputar con sus semejantes ${ }^{2}$. Algunas veces estas disputas se resuelven en tribunales o asambleas; otras, no; pero dondequiera que terminen, las disputas surgen con frecuencia por un sentimiento de agravio, pero también por cuestiones de honor, dignidad y competencia por el estatus social. Los querellas se arbitran o adjudican cuando se considera que afectan a los intereses de una sociedad más amplia o cuando una de las partes involucradas decide llevarlo hasta sus últimas consecuencias. Cuando esto sucede, la dimensión emocional y competitiva de pleitear se deja de lado y el proceso se centra en el conjunto de hechos disputados. Importantes instituciones sociales - tribunales de justicia, asambleas, árbitros, conciliadores, patrones, señores- consideran las demandas sobre hechos y, a veces, llegan a una conclusión sobre la verdad de dichas reclamaciones. El honor, si es que se considera, se convierte en objeto de un proceso de contabilidad, como en los elaborados cálculos del código Lombardo ${ }^{3}$. Cuando las disputas acaban adjudicadas o arbitradas por una tercera parte, los debates sobre honor y jerarquía se convierten en disputas sobre hechos.

La introducción en una disputa de una tercera parte marca una notable transformación epistemológica. Entre la gente que lucha (feud) o depreda (raid) y la que soluciona sus disputas de un modo directo, los hechos rara vez

2 MoORE, Sally Falk, Law as Process: An Anthropological Approach. Londres 1978; RoBERTs, Simon, Order and Dispute: An Introduction to Legal Anthropology. Oxford 1979; MJLLER, William lan, Humiliation: And Other Essays on Honor, Social Discomfort, and Volence. Ithaca, N.Y., 1993.

3 Entre los códigos germánicos de leyes de la Alta Edad Media, las leyes Lombardas contenian las listas más sofisticadas de pagos por agravios, a la vez que asociaban explícitamente el pago de la composición con el propósito de prevenir la enemistad entre familias. Véase BLUHME, F. (comp.), Leges Langobardorum. Leges, Monumenta Germaniae'Historica, vol. 4. Hanover, 1869.

Hispunia, LVII/3, núm. 197 (1997) 1049-1077 
aparecen como objeto de la disputa pues son perfecta y totalmente conocidos por las partes involucradas ${ }^{4}$. Los litigantes pueden ocultar este conocimiento a los tribunales, a los representantes estatales, a los misioneros o incluso a los antropólogos, pero no los ocultan entre ellos. Esto se debe a que las luchas y rapinas son por cuestiones de honor, $y$ el honor ha de debatirse publicamente. Pero cuando el derecho deja de ser principalmente un proceso de venganza para preservar el honor, y se convierte en un proceso de averiguación de hechos que administra una tercera parte, el problema del conocimiento se coloca en un primer plano.

El conocimiento es un problema en cualquier ámbito en el que hechos o interpretaciones son materia de disputa, pues no es fácil para un observador desinteresado encontrar una fórmula imparcial para diferenciar entre conjuntos opuestos de hechos. Las herejías que desesperaron a la antigua Iglesia cristiana proporcionan un ejemplo del caso en cuestión, así como un solución instructiva. El fin de la era apostólica significó que la revelación, hacia el siglo II, ya no servía para distinguir la creencia verdadera de la creencia falsa. Las herejías basadas en textos no canónicos se combatían fijando el canon de la escritura sagrada, pero una vez que se completo este proceso, en el siglo IV, comenzó a plantearse el problema de las interpretaciones heterodoxas de los textos. Como resultado, dos de las medidas obvias de autoridad y verdad, a saber, la revelación y la autoridad textual, perdieron su capacidad para determinar cuál era la verdadera doctrina dentro y fuera de las mismas. ¿Cómo salir del embrollo? En el año 434, Vincent de Lerins propuso una solución a este intrincado asunto. Al observar que la misma profundidad del texto hacía inevitable la competencia entre interpretaciones, Vincent escribió que la fe católica es «lo que ha sido creído en todas partes, siempre y por todos» 5 . En su fórmula, la creencia verdadera adquiere autoridad en virtud de ser conocimiento común. La prueba de verdad permanece en los más relevantes archivos del conocimiento - testimonio, memoria, documento escrito-y Vincent discutió convenientemente los diversos mecanismos de consulta de estos archivos para distinguir verdad de falsedad.

Aunque se desarrolló para hacer frente a las necesidades especificas de los teólogos del siglo $\mathrm{v}$, la fórmula vicentina expresa de manera oportuna un paradigma de conocimiento que se encuentra en numerosas culturas legales de la Europa noroccidental en buena parte del siguiente milenio. Para apreciar la naturaleza universal y permanente de la fórmula, sólo es necesario examinar una prueba de conocimiento equivalente, si bien más trivial, que se presentó, novecientos años después, al juez del tribunal palatino de la Marsella medieval. El caso enfrentaba al ilustre comerciante Peire Bonafos contra su vecina Gandulfa Pisana. El tema en discusión era un canal de desagüe que

4 Muler, William Ian, Bloodtaking and Peacemaking: Feud, Law, and Society in Saga Iceland. Chicago 1990, pág. 249.

5 Vincent de Lérins, Commonitorium, en Demeulenaere, R., (comp.), Corpus Christianorum, Series Latina, Turnholt 1985, vol. 64, pág. I49. 
pasaba entre la casa de Peire y un solar perteneciente a Gandulfa, un desagüe que había caído en un estado ruinoso debido al descuido del último marido de Gandulfa y al vandalismo de la misma Gandulfa. El comerciante Peire, suficientemente experimentado en el arte de encontrar y recuperar expedientes, todavía no una ciencia en la Marsella medieval, llevó ante el juez la transcripción de una decisión anterior tomada por una especie de tribunal ambulante formado por tres albañiles, llamados extimatores peyreriorum o "albañiles asesores" 6 . La transcripción incluía el testimonio de siete testigos. Uno de ellos, Guilelma de Crusols, una joven de veinticuatro años, había dicho algo parecido a lo siguiente:

Hace al menos doce años, vi una especie de pequeño canal de desagüe entre la casa (la casa ahora pertenece a Peire Bonafos, pero antes fue mia) y el prado perteneciente a Gandulfa. El canal de desagùe recogía los desperdicios de las casas de allí. Los desechos corrían a la calle de St. Jacques. Después de que vendí la casa, el comprador me pidió que le ayudase —el agua estaba entonces metiéndose en su casa, por qué Gandulfa había movido el canal. Así pues, fui a allí y pregunté a Gandulfa por qué había movido el canal. Todo lo que ella hizo fue decír que removería todas las cañerías que se colocasen allí, mostrándome el caño de desagüe extendido en sus manos. Numerosas personas ahora fallecidas tuvieron conocimiento de esto ?.

Otro testigo, Johan Senequier, antiguo albañil asesor, comentando la pretensión del demandante sobre que estos hechos eran ampliamente conocidos, dijo:

Todo esto es de conocimiento público (faman publicam) en la ciudad de Marsella entre las personas del barrio de St. Jacques y entre los albañiles asesores. Preguntado por el significado de "fama», dijo que es lo públicamente hablado entre las personas ${ }^{8}$.

Hay una gran distancia entre las cuestiones heréticas del siglo $v$ y un problema de drenaje del xIV. Sin embargo, ambas situaciones exigen pruebas de conocimiento, y es extraordinario que el paradigma de conocimiento propuesto por Vincent de Lerins en el año 434 no parezca muy distinto del implícito paradigma de conocimiento utilizado en 1338. Se nos dice que los hechos del caso en Marsella son conocidos por todos, que son públicamente compartidos. Son reconocidos en todas partes, no sólo entre los residentes del barrio

' Sus decisiones, llamadas cognitiones extimatorum peyreriorum eran por regla general certificadas ante norario y debidarnente registradas en los libros notariales. Nueve de estas cognitiones extimatorum peyreriorum se pueden hallar en los libros del notario Peire Aycart, en servicio activo en los decenios de 1350 y 1360 ; véanse los Archives Départementales des Bouches-du-Rhône, Francia (en adelante ADBR), 355E 34-36.

7 ADBR 3B 34, fols. 12r-v, 22 de abril de 1338. Se ha condensado el testimonio con objeto de eliminar repeticiones.

8 lbid., fol.13v.

Hispania, LVIL/3, núm, 197 (1997) 1049-1077 
de St. Jacques sino incluso entre el grupo de albañiles asesores, geográficamente más disperso. Se hallan enraizados en el pasado, en los documentos escritos presentados por Peire Bonafos, incluso en las memorias de los muertos. Ciertamente no existía, en la Marsella del siglo XIV, el equivalente de una escritura, ni estudios de expertos o mapas catastrales; no había registros gubernamentales que determinasen el lugar del desagüe y su conservación. La ausencia de pruebas escritas relevantes pone de manifiesto cuál era el estado de los archivos de conocimiento en el siglo xIV: principalmente, recuerdos; secundariamente, escritos. Pero incluso así, la verdad se determinaba de una manera muy similar: el conocimiento, para ser conocimiento, tenía que hallarse inscrito en los archivos públicos de conocimiento - es decir, ser conocido por numerosas personas del pasado y del presente en toda la ciudad. Vincent de Lerins puede haber desarrollado su doctrina de la autoridad desde una premisa teórica; los jueces, los litigantes y los testigos de la Marsella medieval pueden haber estado actuando de una manera menos consciente o intelectual, pero en ambos casos, la autoridad se medía por el patrón imparcial del conocimiento común, público.

La fórmula vicentina era parte de lo que denomino una «cultura legal de publicidad" Una cultura legal en la que la metáfora es ser abierta y dar publicidad a todo lo que se dice y hace. Como veremos en el caso de la Marsella bajomedieval, las exigencias de esta cultura legal de publicidad conformaron la conducta en un grado considerable. Los hombres y las mujeres por lo general necesitaban actuar abiertamente y en público con el fin de registrar los hechos en las memorias y redes de chismorreo que componían el archivo del cual podría depender la prueba en los pleitos legales posteriores ${ }^{9}$. El objetivo de la sección que sigue es ilustrar este punto. Pero no eran sólo los individuos quienes, en ciertas circunstancias, se comportaban abierta y públicamente: en la Marsella del siglo XIV los tribunales legales se reunian de puertas afuera, e incluso la cultura escrita de los notarios, un rasgo prominente de numerosas áreas de la Europa mediterránea después del siglo XI, era una cultura legal muy divulgada. De este modo, el mismo sistema legal formal era consciente de la necesidad de actuar públicamente.

Tal comportamiento público creó archivos de conocimiento basados en memorias que complementaban y ampliaban los archivos escritos disponibles. La segunda sección del artículo ilustra cómo se utilizaban estos archivos en caso de litigio. Los tribunales conformes al derecho romano que actuaban en la Marsella del siglo xiv, quizás en mayor medida que los tribunales medievales anteriores, exigían hechos - hechos sobre la edad, el parentesco, el título, la posesión de bienes muebles, la condición marital, la fecha de nacimiento, de fallecimiento, y otros. Paradójicamente, los archivos de conocimiento escrito, con la gran excepción de los casos relativos al crédito y a las deudas, no regis-

9 Véase Halbwachs, Maurice, Mémoires collectives. París, 1950; Clanchy, M. T., From Memory to Written Record, 1066-1307. Londres, 1993, 2." ed.; NorA, Pierre (comp.), Les lieux de mémoires, 3 vols. Paris 1984-1992; CARRUTHERS, Mary, The Book of Memory: A Study of Memory in Medieval Culure. Cambridge, 1990; GEARY, Patrick J., Phantoms of Remenbrance: Memory and Oblivion at the End of the First Millennium. Princeton, 1995.

Hispania, LVI]/3, nủm. 197 (1997) 1049-1077 
traban (hasta ese momento) muchos de estos hechos de manera sistemática. ¿Cómo, entonces, en casos complejos de litigio, discernían los jueces entre recuerdos y relatos opuestos que les presentaban los litigantes? Un estudio de diversos casos sugiere lo siguiente: los litigantes esperaban que los jueces oirían no sólo los hechos presentados por los testigos, sino que también prestarían atención al perfil social del grupo informado (Knowledge-bearing group) reunido por los litigantes. De manera significativa, los litigantes que eran capaces de reunir el grupo de testigos socialmente más diverso ganaban consistentemente sus casos. Actuaban así porque podían ilustrar de una forma relativamente mecánica cómo sus reclamaciones cumplían las exigencias imparciales de la fórmula vicentina que hacía idénticas verdad y universalidad.

De acuerdo con estos argumentos, la cualidad más característica de la cultura legal medieval no era que fuese oral o escrita, sino más bien su publicidad. Para decirlo de otra manera, la división entre lo oral y lo escrito, que habitualmente trazamos cuando describimos técnicas medievales para registrar porciones de conocimiento, no sirve para comprender las formas del conocimiento y su utilización en los tribunales legales en la Marsella del siglo XIV -y, por extensión, en cualquier otra parte de la Europa medieval. Más útil es una dicotomía que distinga lo público de lo secreto. Estas dicotomías no son idénticas: lo público no es necesariamente lo oral, y lo secreto no es necesariamente lo escrito. Los archivos de conocimiento escrito adquieren la autoridad de la publicidad cuando se crean ante la mirada pública, como sucedía en la Marsella del siglo XIV. Por la misma razón, el conocimiento basado en la memoria oral tenía escasa autoridad en los tribunales si era visto como limitado a grupos privados y pequeños de parentela y dependientes.

Si utilizamos publicidad como criterio medible, encontramos considerables continuidades a lo largo de la Edad Media. Aunque los archivos de conocimiento se engrosaron con la creciente utilización de los instrumentos escritos de deuda y obligación a partir del siglo xII, la cultura legal de la publicidad permaneció como una costumbre legal fundamental. Una importante premisa de este artículo es que esta cultura legal de la publicidad declinó en dos momentos entre los siglos XVI y XIX: el primero, cuando el derecho se transfirió de puertas adentro; y el segundo, hacia finales del siglo XIX, a medida que las técnicas forenses y las pruebas circunstanciales surgieron como herramientas con las cuales desafiar, no corroborar, la evidencia de lo visto y oído. La utilización de la escritura, a la par que los intereses rápidamente emergentes de los Estados y las sociedades civiles, contribuyeron a este cambio. Esto, sin embargo, nos llevaría más allá de los límites de este artículo. En lo que sigue me sentiré satisfecho con perfilar una arqueología preliminar del conocimiento legal, tomando la cultura legal de la Marsella de mitad del siglo XIV como representativa de costumbres legales europeas más generalizadas.

\section{LA CULTURA LEgal dE LA PURLICIDAD}

Como es bien conocido, los hombres y las mujeres en la Edad Media difundían información sobre sus actividades, identidades y posesiones con un entu-

Hispania, LVIL/3, núm. 197 (1997) 1049-1077 
siasmo y energía difíciles de exagerar. Los ajuares de boda eran llevados públicamente a través de las calles a fin de permitir que los vecinos juzgasen el valor de la novia y, por lo tanto, la condición social y generosidad de su padre, y para demostrar que se había pagado la dote ${ }^{10}$. Las ropas y los peinados informaban sobre la condición social; los regalos se intercambiaban de manera que todos pudieran verlos, y cuando se moría, se hacía a la vista del público ". La característica crucial de estos hechos de publicidad es que no sólo cumplían un servicio en el ciclo interminable de conversaciones sobre reputación, honor, condición social y poder, sino que también podían tener importantes derivaciones legales. En la saga islandesa, los homicidios debían ser cometidos abiertamente y anunciados públicamente si el asesino quería evitar el estigma de la ocultación ${ }^{12}$. En Lombardía, la copulación, esencial para la validez legal del matrimonio, tenía que ser presenciada por testigos ${ }^{13}$.

Los ejemplos en los registros judiciales de la Marsella del siglo XIV son suficientemente abundantes como para mostrar que la necesidad de hacer público todo lo que se hacía no era una reliquia pintoresca de la costumbre oral germánica: se trataba de una práctica profundamente imbricada en la cultura legal de la Europa bajomedieval. Esto lo vemos en el constante uso de diferentes formas de la palabra "público" y en el uso de la palabra palam en las actas de tribunales y registros notariales, como muestran los siguientes ejemplos. Vemos como el viguier de la ciudad favorece abierta y públicamente (palam et publice) a una facción noble ${ }^{14}$. Un notario que redacta un documento de préstamo exhibe monedas en una mesa delante de él y luego recita y publica (recitavit et publicavit) la deuda contraída ${ }^{15}$. Un hombre es considerado abierta y públicamente el padre legítimo y natural de su hijo por sus vecinos y conocidos (peire Bonifacii est pater et legitimus et naturalis dicti Amelii et pro tali habetur et reputatur... palam et publice inter notos et vicinos) ${ }^{16}$. Un hermano y una hermana arriendan abierta y públicamente puestos en el mercado (locaverunt aliquas tabulas... palam et publice) ${ }^{17}$. Por otra parte, una mujer de laxa moral se convierte en una prostituta tan pronto es considerada publicamente (meretris publica) ${ }^{18}$; los insultos hechos abierta y públicamente

\footnotetext{
10 KlaPISCH-ZUaer, Christiane, La maison et le nom: stratégies et rituels dans ITalie de la Renaissance. París 1990, págs. 220-224.

11 Sobre la vestimenta, véase HUGHES, Diane Owen, «Regulating Women's Fashion», en Christiane Klapisch-Zuber (comp.), Silences of the Middles Ages. Cambridge, Mass., 1992: A History of Women in the West, DuBY, Georges y Perrot, Michejle (comps.), vol. 2, págs. 136-158; sobre la muerte, véase DuBY, Georges, Guillaume le Maréchal, Paris, 1984.

12 MILLER, Bloodtaking and Peacemaking, op. cit., págs. 249-250.

13 Hughes, Diane Owen, «Il mattimonio nell'italia medievale», en Gıorgio, Michela de y KLAPISCH-ZUBER, Chistiane (comps.), Storia del matrimonio. Roma, 1996, pág. 30.

14 ADBR 3B 820, fol. 46v, 7 de julio de 1356.

15 ADBR 3B 38, fol. 110 r, 20 de julio de 1339.

I6 ADBR 3B 820, fol. 47r, 7 de julio de 1356.

17 ADBR 3B 37, fols. 249v-250r, 21 de mayo de 1339.

18 Ejemplo de ADBR 3B 58, fol. 105v, 19 de febrero de 1355 .
} 
son mucho peores ${ }^{19}, \mathrm{y}$ alardear públicamente del involucramiento en un asesinato equivale a una confesión ${ }^{20}$. De manera similar, reunirse de forma secreta y evasiva (clam et occulte) ${ }^{21}$ no es una pauta de conducta honesta, ni se pueden cambiar los elementos de una casa clam et occulte sin levantar las sospechas de los vecinos ${ }^{22}$. No se posee tierra de una manera secreta ${ }^{23}$. Las cuestiones de registro público, tales como las decisiones concejiles y las excomuniones, se anunciaban públicamente en calles, mercados e iglesias. Sabemos, por un caso de tribunal de 1343, que todos los brujos y hechiceros que practicaban su oficio secreta y evasivamente (clam et occulte) eran de forma regular excomulgados publicamente en las iglesias de Marsella ${ }^{24}$.

La frecuente utilización de palabras como palam y publice es una prueba sencilla de la importancia de la publicidad, y el testimonio en casos de tribunales revela la importancia de la divulgación de comportamientos y hechos incluso aún cuando no se utilizaran estas palabras. Era normal, por ejemplo, que la muerte de una persona fuese proclamada abiertamente por su parentela, y este acto de publicidad fuese observado y muy comentado por los vecinos. Como dijo un testigo llamado Johan Barratan en un caso,

hace dos años aproximadamente que él, el testigo, era vecino de Guilelma Gamelła, que vivía en la casa de su hija Pellegrina. Cierto día que no recuerda, en torno a la hora del canto del Ave María, mientras se hallaba en su propia casa, escuchó a la hija Pellegrina lorar en voz alta y lamentarse por su madre Guilelma, que agonizaba. Al escuchar a Pellegrina llorar y lamentarse, entró en la casa de Pellegrina y la encontró medio muerta, diciendo que Guilelma había muerto 25 .

En otro caso, un testigo oyó decir «por toda la gente de la calle» que a un tal Girart Marro la muerte le había llegado de repente y que la expresión de dolor "Mort es ses lenga, mort es ses lenga en Girart Marro" estaba en la boca

19 ADBR 3B 37, 14 de julio de 1339, hoja suelta entre los fols. 279-280. «Bernat.. palam et publice in presencia multorun proborum et in pluribus et diversis locis dicte civitate... appellavit eundem Johannem bastardum...\%.

20 ADBR 3B 820, fol. 90r, 7 de julio de 1356. Amelius publice diffamavit quod ipse est consocius mortis dicti Petri [de Jerusalem].

21 Ibid., fol. $12 r$.

22 ADBR 3B 816, fol. 24v, 17 de junio de 1353; ADBR 3B 64, fol. 9r, 22 de octubre de 1362.

23 ADBR 3B 812, fol. 53v, 28 de julio de 1352 . El demandante deciaró que poséa un terreno de una forma no secreta (non clam).

24 ADBR 3B 45, fols. 170r-180v, 15 de octubre de 1343.

25 ADBR 3B 38, fol. 65v, 14 de octubre de 1339: «Quod ipso existente vicino dicte Guillelma Gamelle in domo dicte Pellegrine filie sue bene sunt duo [sic] anni elapsi quadam die de qua non recolit, circa pulsationem Ave Marie, dum ipse testis esset in domo sua, audivit clamantem alla voce Pelegrinam Gamella filiam et plagentem dictam Guillelmam matrem suam quia iam mori incipiebat. Qui testis, audiens dictam Pelegrina clamantem et plangentem, intravit domum dicte Pelegrine et invenit eam quasi semis mortuam, dicens etiam quöd mortua dicta Guillelma».

Hispenia. LVJ//3, nüm. 197 (1997) 1049-1077 
de todos ${ }^{26}$. La fecha de fallecimiento, un dato legal importante, podía divulgarse de otras maneras. En noviembre de 1362, poco después de que un segundo brote de peste hubiera devastado Marsella, se falló una disputa sobre una herencia que dependía de la fecha de la muerte en favor de la viuda del difunto, porque sus vecinas pudieron testificar que habían visto a la desolada mujer "yendo a la iglesia con ropas de viuda, como es costumbre" ${ }^{27}$. En un caso semejante, esta vez en medio de la primera peste en abril de 1348, las mujeres de la vecindad pudieron informar que habían visto dos procesiones de entierro sucesivas y, por medio de su testimonio, pudieron probar la reclamación del litigante de que su hija había muerto después de su mujer, por lo que se convertía en el heredero de ambas ${ }^{28}$. De manera similar, mujeres de la vecindad fueron llevadas ante tribunales para probar la fecha de nacimiento y la legitimidad de parentesco, y, aunque los documentos existentes no mencionan ceremonias de nacimiento, con las consiguientes derivaciones legales y archivísticas, no es difícil imaginar cómo pudieron anunciarse públicamente los nacimientos ${ }^{29}$.

La propiedad de bienes muebles se establecía por testigos —amigos, vecinos, sirvientes- que hubieran visto a sus propietarios utilizarlos de forma abierta. La costumbre de solicitar a vecinos que testificasen en el último testamento de una persona y luego permaneciesen velando el cuerpo del difunto fue, como muestran algunos casos, un mecanismo particularmente importante para la creación de un archivo de conocimiento sobre las posesiones individuales ${ }^{30}$. Johan Barratan, cuyo testimonio fue citado anteriormente, continuó informando de lo siguiente:

El testigo y todos sus vecinos que vivían en la calle de Pellegrina permanecieron velando el cuerpo o cadáver de Guilelma y se quedaron cerca de él prácticamente durante toda la noche; y cree que Pellegrina ha mantenido y controlado la cama en la que Guilelma yacía y todas las otras cosas o ropas que se hallaban en la casa de Pellegrina ${ }^{31}$.

${ }_{26}$ ADBR 3B 45, fol. 147r, 16 de agosto de 1343: «Interrogatus testis qua morte obiti dictus Girardus condam, dixit quod subitanea morte, ut dici audivit per omnes gentes dicte carrerie, comuniter proferentes verba hec, «Mort es ses lenga, mort es ses lenga en Girart Marro».

${ }^{27}$ ADBR 3B 64, fols. 50r-59r, 8 de noviembre de 1362.

28 ADBR 355E 292, fols. 48r-50v, 10 de abril de 1348 .

29 Dos casos interesantes que tratan del nacimiento se halian en ADBR 3B 38, fols. 63r-66v, 14 de octubre de 1339 (el demandante necesitaba establecer su edad correcta), y ADBR 3B 64, fols. $65 \mathrm{r}-71 \mathrm{r}, 10$ de noviembre de 1362 (la demandante necesitaba establecer la legitimidad de su parentesco).

30 ADBR 3B 38, fols. 63r-66v, 14 de octubre de 1339; ADBR 3B 816, fols. 12r-67v, 17 de junio de 1353: ADBR 3B 43, fols. 21r-36r, 30 de agosto de 1341 .

31 ADBR 3B 38, fol. 65v, 14 de octubre de 1339: «lpse testis et vicine sue omnes de carreria dicte Pelegrine corpus seu cadaver ipsius Guillelme vigilartut et iuxta ean steterunt quasi per totam nocte; et credit quod lectum in quo ipsa Guillelma iacebat et alie res seu vestes si que erant in domo dicte Pelegrine, dicta Pelegrina habuerit et rexerits.

Hispania, LVIJ/3, núm. 197 (1997) 1049-1077 
La propiedad de una casa se demostraba sencillamente con la entrada y salida del lugar, pero también por la abierta posesión de las llaves, lo que, en algún caso, sirvió también para probar quién era el marido de una mujer ${ }^{32}$.

Es en los asuntos de propiedad de bienes inmuebles donde encontramos el mayor interés en hacerla pública de todas las formas. En la mayoría, si no en todos los sistemas legales europeos, el título de propiedad se hallaba íntimamente asociado con el disfrute útil de la propiedad en cuestión ${ }^{33}$. Los ejemplos de los tribunales de Marsella muestran que era esencial pagar la renta y los impuestos abierta y públicamente como signo de la posesión pacífica de propiedad ${ }^{34}$. La tierra de uso agrícola tenía que ser explotada abiertamente ${ }^{35}$. Se debían realizar rituales prescritos cuando se tomaba posesión de una propiedad (intrare possessionem).

Un ejemplo excelente de lo anterior, digno de explorar con cierto detalle, puede encontrarse en una disputa sobre una bastida, una vasta tenencia provenzal de tierras agrícolas que incluía una casa y construcciones exteriores. El caso enfrentaba a un hombre con la viuda de su tío. Poco antes del 24 de julio de 1343, cuando se originó la disputa, el tío, Jacme Macel, había muerto, dejando la bastida a su viuda Beatrix ${ }^{36}$. El sobrino del difunto, Bertran, consideró esta pérdida como una gran injusticia y, el mismo día de la muerte de su tío, reunió a un grupo de testigos, incluyendo al notario Guilhem de Pulcravilla, a un amigo llamado Peregrin Arnos y a su propio cuñado, Jaufres Isnart, y se dirigió al campo para tomar posesión de la casa. Sus actos se ajustaban a los preceptos del derecho romano que regulaban la adquisición de propiedad, a pesar de que aparentemente no tenía derecho legítimo alguno a la bastida. De este modo, empezó una serie de actos dirigidos a inculcar en los testigos el hecho de su propiedad.

En primer lugar, en el camino reunió a dos segadoras, Alazais Pellegrina y Francesca de Roceto, que se hallaban en la plaza de Lauret en espera de trabajo. "De buena gana", le contestaron cuando les preguntó si les gustaría cosechar diversos frutos en su propiedad rural. En otra parte del camino a la bastida, llamó al molinero Johan Guilhem, que trabajaba en su molino, para

32 ADBR 3B 812, fol. 33r, 1 de junio de 1352. La evidencia debatida en un caso encontrado en ADBR 3B 808, fols. 228r-272r, 25 de octubre de 1342, ilustra cómo la propiedad de ias llaves tiene fuerza en cuestiones de título.

33 Nicholas, Barry, An Introduction to Roman Law. Oxford 1962, págs. 120-129; KUEHN, Thomas, Law, Family, and Women: Toward a Legal Anthropology of Renaissance Italy. Chicago 1991, págs. 108-111.

34 Sobre el pago de impuestos como prueba de propiedad, véase ADBR 3B 53, fols. 22r-25v, 16 de septiembre de 1353; sobre el pago de renta, véase inter alia ADBR 3B 34, fol. 141 v, 18 de octubre de 1338, y ADBR 3B 812, fol. 34v, 1 de junio de 1352: «...dixit quod fama erat quod dictum hospicium erat suum et etiam vidit dictum magistrum Johannem solvere censum seu servicium dicti hospicii camarario monasterii Sancti Victoris sub cuius maiori domino ... dictum hospicium tenetur...,s.

35 ADBR 3B 52, fols. 161r-v, 11 de diciembre de 1353.

36 ADBR 3B 45, fols. 94r-14lv, 24 de julio de 1343. 
que se le uniese, y también invitó a uno de sus trabajadores. Una vez allí, se volvió en primer lugar hacia el molinero y le dijo: «Señor, sabed como mi testigo que he entrado y tomado posesión de esta bastida de mi tío Jacme Macel, y de todo el terreno que le pertenecen. En ese momento, el notario, que se había detenido en el camino para orinar, llegó apresurándose, a tiempo para que Bertran le dijese: «Levanta acta de cómo entré y tomé posesión de esta bastide y de su tierra». Luego insultó al agente de Beatrix, que habra llegado a la bastide antes que él, y le exigió que le entregase la llave, a lo que el agente le respondió que no podía resistirse, y lo hizo. Mientras tanto, las dos mujeres se ocupaban de recoger la fruta de los frutales, y Bertran se acercó a ayudarlas. Juntos cargaron un asno con una carga completa de fruta para llevarla a la ciudad. Más tarde, se encontró a algunos hombres que pasaban por el camino y les pidió si querrían llevar tres sacos de grano a la ciudad para vender por cuenta de él. Todo este trabajo era prueba de uso y posesión; de ahí el deseo de Bertran de inculcarlo en las mentes de los testigos.

Bertran perdió al final su pleito, y el suyo es uno de los pocos casos conservados de la Marsella medieval en el que un litigante haga oídos sordos a la idea de que un acto escrito -en este caso, un testamento- otorgaba a su beneficiario derechos legales que serían reconocidos y defendidos por los tribunales. Lo significativo aquí no es su fracasado intento de prestidigitación legal, sino más bien la naturaleza pública del proceso de posesión. Cada nuevo propietario, incluso los que tenían más derechos legales que Bertran, debían ejecutar los rituales que creaban conocimiento público del cambio de propiedad. A falta de un título legal contenido en un instrumento escrito, como en los casos de sucesión abintestada, un proceso de apropiación muy difundido creaba un archivo de conocimiento que más adelante podía servir como prueba de propiedad. Muchos casos de la Marsella del siglo XIV nos muestran con qué frecuencia este archivo de la memoria se utilizaba en disputas de propiedad; de hecho, rara vez se encuentran títulos escritos en los tribunales de Marsella ${ }^{37}$.

La cultura legal medieval era, por tanto, en muchas de sus facetas, de orientación manifiestamente pública, y por ello un mecanismo eficiente para inscribir hechos en el registro público; como hemos visto en todos estos casos, los litigantes recurrían a estos hechos cuando lo necesitaban. Por supuesto, la publicidad puede ser obtenida de manera no intencional, pero el valor concedido a la conducta pública sugiere que la gente era consciente de la necesidad de actuar abiertamente. "Recuerde que me ha visto cultivando este trozo de propiedad", le pidió un trabajador llamado Johan Trohin a un forastero que que un día de 1352 pasaba por alli ${ }^{38}$. Se acercó a otros cuatro hombres diciéndoles las mismas palabras y más tarde consiguió llamar a estos cuatro testigos para probar lo que se había propuesto.

${ }^{37}$ Algunos de estos casos los trato en «Notaries, Courts, and the Legal Culture of Late Medieval Marseille», de próxima aparición.

3* ADBR 3B 812, fol. 64v, 28 de julio de 1352; «...recordete tibi ad memoriam quod tu me vides podantem istam possesssionem...). 
Uno de los rasgos más notables de la cultura legal de la publicidad es que se extiende igualmente a la presentación pública del derecho formal. En toda Europa occidental, la elaboración y búsqueda de leyes con frecuencia eran cuestiones públicas. Las proclamaciones que emanaban de organismos oficiales eran comunicadas al público por heraldos o pregoneros ${ }^{39}$. En Marsella, como en otras localidades, los mismos tribunales se convocaban en el exterior, «reuniéndose ante la casa de los herederos del último Pons Durant donde habitualmente los jueces resuelven los pleitos», 0 «delante de las puertas bajas de la iglesia de María Bendita de Accoules donde sus señorías los jueces comúnmente se reúnen y juzgan» ${ }^{40}$. Durante la Peste Negra, cuando se hizo insoportable el terrible hedor de muerte que el aire portaba desde el cercano cementerio, el tribunal se trasladó a la atmósfera más limpia del puerto, reuniéndose en los puestos de los banqueros (tabulae cambiorum) en una calle cerca del mar ${ }^{41}$. Los dos tribunales ordinarios de primera instancia también se reunían cerca de la iglesia de Accoules ${ }^{42}$. El tribunal de apelaciones parece haberse reunido en la Plaza del Palacio a mediados del siglo XIV; en el siglo XIII, los documentos sugieren que dicho tribunal se emplazaba en el mismo lugar que el tribunal palatino ${ }^{43}$.

De igual manera, los notarios de toda la Europa meridional eran por lo común muy públicos en sus gestiones; la gran preocupación por fraudes y falsificaciones fue uno de los factores que animaban a los notarios y a sus clientes a no ser sigilosos en las actas que levantaban ${ }^{44}$. Las cláusulas de suscripción de Marsella revelan que con frecuencia los notarios ejercían su trabajo en la calle, delante de sus casas o de las de sus clientes. Las rentas debidas a los grandes señores se recaudaban anualmente por notarios que eran contratados para recorrer la ciudad llamando a las puertas de los cabezas de familia y levantando actas en el momento, frente a la mirada pública. Por otra parte, al elegir testigos para contratos notariales, los notarios y/o sus clientes habitualmente invitaban a extraños elegidos al azar en lugar de amigos cercanos o parientes de los clientes involucrados; esta práctica realzaba la

39 GAUVARD, Claude, «Rumeur et stéreotypes à la fin du moyen âge», en La circulation des nouvelles au moyen âge, op. cit., págs. 162-163.

40 Véase inter alia ADBR 3B 37, fols. 49r-51r, 12 de diciembre de 1338: «...sedente ante domum heredum Poncii Duranti condam ubi judices ius reddere consueverunt ...» $y$ *... ante valvas inferioris ecclesie Beate Marie de Acuis ubi interdum domini judices sedere iusque reddere consueverunt...").

41 Véase ADBR 355E 285, fol, 20r, 30 de abril de 1348.

42 ADBR 3B 58, fol. 60v, 30 de abril de 1345; Archives Municipales de la Ville de Marseille FF 518 , fol. 49 r, 12 de julio de 1340.

43 Véase ADBR 3B 820, fol. 24r, 7 de julio de 1356, que proporciona la ubicación de un acta realizado en el tribunal de apelaciones como la platea Palacii. ADBR 3B 802, fol. $30 \mathrm{r}, 13$ de enero de 1290, localiza el tribunal ante la puerta de Peire Durant (como antes).

44 Una razón para la publicidad notarial puede hallarse también en el escaso significado en sí mismos que tienen los documentos notariales; en general, las cláusulas notariales en las que se identifican clientes, propiedades y otras cosas son ambiguas, lo que indica que era la memoria de los notarios, de testigos formales y de espectadores casuales lo que otorgaba significado al acta.

Hisparia, LVII/3, núm. 197 (1997) 1049-1077 
naturaleza pública y abierta de la transacción. En el caso de un préstamo ante notario, un testigo llamado Johan de Massilia dio el siguiente testimonio:

\begin{abstract}
Llamado por cierta mujer a quien no recuerda, el testigo acudio a una casa perteneciente a Guillelma Cadella situada en la calle del Mercado Alto del Grano de Marsella donde el llamado Hugonet y su mujer solían vivir. Allí encontró al notario Johan Guibert, el joven, al llamado Hugonet, a su mujer, al maestro Peire de Jovis, alias de Lhione, a Jacme Juvenis, al maestro Salamon de Palermo, y a otros dos judíos y otros cristianos cuyos nombres no recuerda ahora.... Esto sucedjó hace cuatro o cinco años. Sobre la mesa o escritorio de la casa se hallaba cierta cantidad de florines que no llegaba, al parecer, a 80 florines... Su nombre fue registrado como testigo del acto y después dicho notario leyó en voz alta y públicamente cómo el citado judío reconocía una deuda de 160 florines a Hugonet. Al escuchar esto, el testigo susurró al oído de Hugonet que no había 80 florines allí, y Hugonet le contestó que por los 80 florines que él daba a los judíos éstos le iban a deber $160^{45}$.
\end{abstract}

Johan no estaba implicado de ninguna manera en la transacción, ni estaba relacionado con ninguna de las partes involucradas, pero su presencia constituyó un elemento importante en la tentativa de Salamon de acusar a Hugonet de usura. El dinero se hallaba esparcido sobre la mesa a la vista no sólo de las partes involucradas y de los dos testigos formales requeridos en casos de deudas, sino también de otras personas que llegaron para testificar la transacción en favor de sus amigos o correligionarios.

La publicidad que acompañaba a la conducta legal formal en la Marsella medieval revela que incluso la misma ley tenía que ser abierta y pública para evitar la nube de sospecha que inevitablemente se formaba en torno a un comportamiento que se consideraba secreto y evasivo. Las ceremonias legales exteriores y abiertas, lo mismo que el reclutamiento al azar de testigos para las actas notariales, contribuyeron al carácter público y honesto del derecho. En otras palabras, la conducta pública se sumó al reconocimiento real o gubernamental para otorgar a los contratos notariales y a las sentencias judiciales la autoridad que conllevaban.

\title{
LA NATURALEZA DEL GRUPO INFORMADO
}

Hemos visto cómo la cultura legal de la publicidad inscribía ciertas clases de hechos en los archivos de la memoria. Estos recuerdos a veces duplicaban los archivos escritos. Con mayor frecuencia la memoria registraba hechos que no estaban disponibles de inmediato por escrito. Esto es particularmente cierto en casos relacionados con la edad, el parentescò, la propiedad de bienes muebles, la condición marital, la fecha de nacimiento y la fecha de muerte, y también en numerosos casos relativos a títulos de propiedad. Con

\footnotetext{
45 ADBR 3B 38, fol. 110r, 20 de julio de 1339.
} 
la importante excepción de los casos de endeudamiento, los jueces en Marsella rara vez esperaban basar sus juicios en una ristra de documentos escritos que ofrecieran pruebas inequívocas en apoyo de una reclamación. Por el contrario, el conocimiento necesario para tales casos estaba disperso en innumerables archivos formados, caso por caso, no sólo por los documentos escritos disponibles sino también, y usualmente de forma más importante, por grupos de testigos y sus recuerdos -0 , para ser más precisos, por las formas en que estos testigos decidían interpretar dichos recuerdos en las sesiones judiciales.

Sin embargo, a falta de técnicas forenses modernas, no era fácil para los jueces probar si lo recordado ante el tribunal reproducía los hechos de manera razonablemente precisa. No era sencillo decidir qué conjunto de recuerdos, qué conocimiento, era el que tenía más autoridad. Por supuesto, los jueces de la Europa meridional disponían de diversos mecanismos para hacer frente a este problema, uno de ellos fue la tortura. Otra fue fomentar el arbitraje que evitaba una resolución tajante. Las historias de algunos litigantes se desmoronaban bajo el peso de sus propias incoherencias. Pero en todos los casos existían soluciones fáciles, y cuando todo parecía fallar, los jueces, siguiendo una versión del siglo XIV de la fórmula vicentina, procuraban averiguar si el conocimiento era compartido en todas partes, siempre y por todos. Si las cosas se habían difundido de la manera adecuada, si un litigante había sido totalmente público en todo lo que él o ella realizaron, entonces el conocimiento de ese comportamiento habría sobrepasado el ámbito familiar del litigante, de sus amigos y dependientes, y habría entrado a formar parte del archivo general de conocimiento, convirtiéndose en conocimiento común, fama publica, "lo que se comenta públicamente por la gente», como Johan Senequier afirmó en $1337^{46}$. Si se daba esta condición, entonces y por lógica, el grupo que sabía, representado por los testigos reclutados por los litigantes, aparecerfa extenso y plural. Los testigos revelarian una serie de lazos sociales con el litigante, incluyendo vínculos no discernibles en absoluto; estos lazos no deberían superponerse demasiado e, idealmente, el grupo incluiría tanto a hombres como a mujeres. La suposición de que el conocimiento verdadero era el conocimiento público permitía a los jueces utilizar una prueba de verdad relativamente mecánica: los jueces podían indagar qué parte se habra

46 En los tratados de jurisprudencia, el papel de la fama, o del rumor y la reputación, fue muy debatido durante la Edad Media. Las siguientes son útiles y recientes introducciones al tema sobre el cotilleo, rumor y reputación en ámbitos legales y literarios de la Edad Media: WicKHAM, C. J., Gossip and resistance among the medieval peasantry. Birmingham, 1995; GAUVARD, Claude, "De grace éspecial», Crime, état et societé en France à la fin du Moyen Âge. Paris, 1991, vol. 1, págs. 135-143; Migliorino, F, Fama e infamia. Problemi della societá medievale nel pensiero giuridico nei secoli XIt $e$ XIII. Catania, 1985; La circulation del nouvelles au moyen âge, XXIV" Congrès de la Société des Historiens Médiévistes de l'Enseignement Supérieur Public. Roma y Paris, 1994; La renommée, número especial de Medievales. Langue, Textes, Histoire 24 (1993); Courtemanche, André, «La rumeur de Manosque: femmes et honneur au XIv siècle», en DÉprez-Masson MarieClaude (comp.), Normes et pouvoir à la fin du moyen âge. Actes du colloque *La recherche en études médiévales au Québec et en Ontariom, 16-17 de mayo de 1989, Montreal, 1989.

Hispania, LVII/3, nùm. 197 (1997) 1049-1077 
acercado más a las exigencias de la fórmula vicentina examinando cómo los litigantes habian reclutado a los testigos y calibrando el grado de conocimiento de esos grupos informados.

Lo anterior es, desde luego, una deducción. Contamos con muy pocos datos directos que nos informen acerca del modo en que estos jueces analizaban las reclamaciones conflictivas. Aun así, esta es la forma más plausible para explicar porqué los grupos de testigos llevaban la marca de la diversidad en muchos de los litigios de la Marsella medieval. Lo que parece claro es que los litigantes, en sus intentos de convertir la materia prima de la memoria en un caso convincente, se cuidaban de reunir un conjunto de testigos que mostrase la naturaleza enteramente pública del conocimiento en cuestión. La frecuencia de la práctica hace pensar que se trataba de una táctica común y deliberada utilizada para influir en las decisiones del juez.

Encontramos ejemplos claros del interés judicial en el proceso de reclutamiento testifical cuando los posibles testigos eran parientes, dependientes o íntimos amigos. Obviamente, los individuos más sospechosos de cualquier grupo de testigos eran los miembros de su grupo de parentesco, y una de las ordenanzas de la ciudad prohibía expresamente el testimonio de parientes ${ }^{47}$. Dado que todo el mundo perecía saber esto, las objeciones por razones de parentesco afectaban en general a testigos cuyos vínculos no eran los de la familia nuclear o de matrimonio. Aquí era donde se daban las mayores incertidumbres, donde los litigantes deseaban tener la oportunidad de que los jueces no excluyeran el testimonio de antemano, o incluso tenían la esperanza de que la relación no fuera descubierta. Por ejemplo, en un caso expuesto más adelante con detalle, el noble Laurent Ricau, al ser preguntado por el juez sobre si estaba relacionado de algún modo con la litigante Johaneta Bonipara, dijo que no, si bien añadió que Johaneta era su comadre (commater). Además, él era viudo y su última mujer había sido prima de Johaneta ${ }^{48}$. En otro caso, Bonafos Chaulet explicó al juez que la litigante Bertrana Berengiera era la esposa de su suegro (al parecer, una segunda esposa). En un tercero, Johan Vivaut dijo que Amiel Bonafos era pariente pues la mujer de éste era hija de cierto primo suyo. En el mismo juicio, y al hablar de la misma muchacha, Uguo Vivaut, familiar de Johan, «dijo que él no era pariente de Amiel excepto en la medida que Amiel estaba casado con su prima" ${ }^{49}$.

47 Les statuts municipaux de Marseille, comp. y trad. de PERnoud, Régine, Mónaco y París, 1949, págs. 87-88. Sobre el reclutamiento de testigos, véase los estatutos titulados De forma in qua debeant produci testes in Massilia vel extra Massiliam. Qui non admittuntur ad testimonium y los estatutos siguientes De eodem y De testibus cogendis et non cogendis. Las normas excluían especificamente el parentesco, como se dice en De testibus cogendis...: Ordinamus presenti capitula ne parentes contra filios vel pro filits... in testimonium nullatenus admittantur (el estatuto se abria con el nombre y excluia todas otras relaciones, llegando eventualmente a omnes ulteriori linea consanguinatis vel affinitatis conjuncti). Ningún litigante podía testificar en su propio favor.

48 ADBR 3B 58, fol. $98 \mathrm{v}, 19$ de febrero de 1355.

49 ADBR 3B 820, fol. 76r, 7 de julio de 1356. 
Los anteriores fueron casos en los que los jueces intentaron descubrir la postble relación entre litigante y testigo. En otras ocasiones, los litigantes trataban de impugnar un testimonio hostil ofreciendo sus propios testigos acerca del grado de relación. En una apelación interpuesta por Amiel Bonafos en 1356, un oficial real intentó anular el testimonio favorable a Amiel demostrando que dos de los testigos, Johan Macel y Carle de Montoliu, eran parientes consanguíneos de Amiel ${ }^{50}$. Nos enteramos de que Johan era en verdad primo por parte de madre. Otro testigo, Peire Austria, desconociendo el grado preciso, declaró simplemente que Johan era miembro de la parentela o grupo familiar de Amiel ${ }^{51}$. En otro caso más, Johan Girman trató de refutar el testimonio contrario de una tal Ugueta Segueria diciendo que Ugueta era sobrina de la litigante con quien se enfrentaba, Jacma Thomasia, una tabernera. Jacma admitió el parentesco, aunque descubrimos que Ugueta era de hecho sobrina del marido de Jacma y no propiamente suya. Marin Morlan, pastor de ganado, impugnó el testimonio adverso de Uguo Raymon y de su hijo Andrieu reclamando que eran parientes en segundo grado de su acusador ${ }^{52}$; los dos testigos de este caso demostraron que los hombres en cuestión eran afines, emparentados por medio de la mujer de uno de ellos. En un último ejemplo, el testigo Carle Athos, al ser preguntado sobre si estaba emparentado con Amiel Bonafos, dijo que no, «aunque es cierto que Amiel tomó como esposa a la hermana del testigo, ahora difunta, y de la que no sobrevivieron hijos» ${ }^{53}$.

Además del parentesco, las acusaciones más comunes contra los testigos adversos se basaban en la dependencia y en las relaciones domésticas (commensal) ${ }^{54}$. En un caso, Bernat Raymbaut impugnó el testimonio contrario de una tal Jacma Colrata argumentando que Jacma era una sirvienta (domestica et familiara) de la demandada Jacma Bernicia, que vivia en su casa y comía y bebía y hablaba con ella (comedendo, bibendo et conversando) ${ }^{55}$. En otro, Raynaut de Conchis impugnó el testimonio adverso de Berengiera Lamberta argumentando que ella era doncella de la demandada Garcenda Imberta, comiendo, bebiendo, compartiendo una cama y trabajando a su servicio ${ }^{56}$. La pobreza era una acusación relacionada, pues implicaba dependencia. En un caso, el juez Peire Dalmas pensó que era necesario preguntar a la testigo Aycarda Salona, una mujer pobre, si era sirvienta de la litigante Jacma Thomasia: «¿comfa y bebía el pan y el vino de la llamada Jacma?" Respondió que no ${ }^{57}$.

\footnotetext{
50 Ibid., fol. 90r: «..consanguiney, domestici, et familiares dicli Amelii».

51 Ibid., fols. $90 \mathrm{r}, 93 \mathrm{v}, 95 \mathrm{r}$.

52 ADBR 3B 43, fol. 12r, 12 de julio de 1341.

53 ADBR 3B 820, fol. 74v, 7 de julio de 1356 .

54 Otros dos factores que restaban fuerza al testimonio eran el mal carácter (se realizaban impugnaciones contra testigos que bebian, blasfemaban y jugaban) y la enemistad preexistente por parte del testigo.

35 ADBR 3B 816, fol. 44v, 17 de junio de 1353.

56 ADBR 3B 43, fol. $31 \mathrm{r}, 30$ de agosto de 1341: «...comedendo, bibendo, iacendo, et participando et eius servicia faciendo....

57 ADBR 3B 37, fol. 267v, junio de 1339.

Hispania, LV]U/3, núm. 197 (1997) 1049-1077
} 
A juzgar por estos datos, el sistema judicial de la Marsella medieval era hostil a las memorias confinadas en grupos pequeños, grupos cercanos basados en lazos de parentesco y dependencia. Sin embargo, la principal dificultad de un sistema que excluye rígidamente el testimonio de personas asociadas muy de cerca con los litigantes es que en muchos casos el suyo es el mejor testimonio. En la disputa por una propiedad discutida antes brevemente, un testigo llamado Alexander Girart dio testimonio para probar que Jacma Augeliera era viuda de Johan de Tholosa. Reveló que él comía y bebía con frecuencia con la pareja (bibit et comedat cum eis) ${ }^{58}$. El siguiente testigo, Johan Julian, cuando le preguntó el juez cómo supo que Jacma se había casado con Johan, también respondió que bebía y comía a menudo con ellos (bibit et comedis pluries in hospicio cum eis) ${ }^{59}$. Si un juez se decidiía a excluir rígidamente el testimonio de tales personas, entonces resultaba muy difícil para cualquier litigante establecer los hechos de su caso con autoridad.

Diversos casos de la Marsella del siglo XIV revelan la solución siguiente a esta paradoja: los litigantes corroboraban de manera rutinaria el testimonio posiblemente sospechoso, pero bien informado de gentes cercanas, especialmente de vecinos, utilizando el testimonio de testigos que se hallaban social y geográficamente más distantes. En el caso de Bertran Macel descrito anteriormente con detalle, hemos visto ya cómo Bertran imprimió el hecho de su toma de posesión de la bastida en una amplia variedad de personas. Éstas incluían a un afín (su cuñado), a sus semejantes (un molinero vecino y un amigo), a sus inferiores (las mujeres cosechadoras, a los trajinantes que pasaban y al trabajador del molinero) y a la ley (el notario Guilhem). Todas estas personas llegaron a testificar en su favor en el pleito posterior ante el tribunal. El grupo informado resultante era impresionantemente diverso, pues iba desde un pariente (su cuñado) hasta trabajadores pobres y mujeres.

Otros grupos de testigos, como veremos en los cuatro casos siguientes, tienen características sociales notablemente similares. El primer caso, de 1341 . tuvo que ver con una disputa sobre la propiedad de una cama. En un determinado momento de agosto de ese año, el zapatero Guilhem Imbert yacía enfermo de muerte en su casa ${ }^{60}$. Ésta se hallaba en el barrio de los zapateros conocido como la Grolaria, en el sexmo de St. Jacques sobre la Calle Nueva. Garcendis, la mujer de Guilhem, sintiendo que su muerte era inminente y deseando reunir a los parientes del agonizante, le pidió al zapatero Guilhem Picart, que vivía enfrente en la misma calle, que fuese de inmediato a las casas de Alazis Ricava y Raynaut de Conchis, sobrina y sobrino del agonizante, y les comunicase la grave situación en la que se hallaba su tío. Sólo el sobrino Raynaut contestó a sus llamadas. Al llegar a la casa de su tío y conseguir atravesar la multitud de vecinos que se hallaban reunidos alrededor del lecho de muerte, Raynaut preguntó a su tío cómo se sentía. Guilhem pareció decir que

58 ADBR 3B 812, fol. 32v, 1 de junio de 1352.

59 lbid., fol. 33 r.

60 ADBR 3B 43, fols. 21r-36r, 30 de agosto de 1341.

Hispania, LVIl/3, núm. 197 (1997) 1049-1077 
no estaba demasiado mal. El sobrino, con poco tacto, continuó preguntando al agonizante: "Señor, ¿recuerda la cama que le presté hace algún tiempo?» Al llegar a este punto, el testimonio relativo a este caso se divide. Según Raynaut y sus testigos, la respuesta de su tío fue una enérgica: «Garcendis, dale la cama a Raynaut", a lo que Garcendis respondió que lo haría, por lo que Raynaut se volvió hacia la gente allí reunida y, siguiendo el principio de que los hechos deben ser registrados en las memorias de los testigos, dijo: "Prestad atención en mi favor, vosotros testigos, de estas palabras pronunciadas por Guilhem y su mujer, tal como habéis oído» (dictus Raynaudus tunc dicte testi et nonnullis aliis personis ubi stantibus dixit «Sitis mihi testes de predictis verbis per dictum Guillelmum et eius uxorem prolatis ut audistin). Por el contrario, el testigo Guilhem Picart, que había acompañado a Raynaut a la habitación, informó que Guilhem, medio muerto y privado de sentido (semimortuus et de sua bona memoria derelictus), dijo: "Se halla arriba, y si la encuentras, cógela», lo que implicaba que no se hallaba en plena posesión de sus facultades y por lo tanto que su asentimiento no tenía valor.

La disputa terminó en juicio. Diversos testigos testimoniaron en favor de la viuda, Garcendis. Éstos incluían a la doncella que vivía en la casa del hombre agonizante, pero el testimonio de esta dependiente cercana fue ampliamente corroborado por una vasta gama de testigos constituida por vecinos, compañeros del oficio no residentes e incluso por un noble llamado Arnaut de Sant Jacme que vivía a varias manzanas de distancia. La única línea de impugnación abierta al sobrino Raynaut fue argumentar que el testigo que había proporcionado el testimonio más perjudicial para su causa, Guilhem Picart, era, al igual que su mujer, miembro de la casa o por lo menos se hallaba al servicio del difunto (familiares et domestice persones dicti Guillelmi Imberti condam). Pero los argumentos de Raynaut no consiguieron establecerse con un despliegue de testigos tan persuasivo y perdió el caso.

El grupo de informantes reunido por Garcendis, la viuda, muestra cómo los hechos eran conocidos no sólo dentro de la casa sino también en la vecindad e incluso por un noble que vivía a varias manzanas. El revelador caso de Antoni d'Ays y su concubina, Dulcia d'Esparon, también demuestra cómo los litigantes estaban ansiosos por establecer que los hechos se conocían dentro de la casa y en la vecindad, fuera de ésta y entre grupos de distintas condiciones sociales ${ }^{61}$. El caso tiene que ver con el intento de ciertos zapateros de la calle Negrel de desalojar a Dulcia, a la que acusaban de ser una prostituta. El caso empezó en serio cuando un enemigo de Antoni, Guilhem de Podio, llevó testigos para probar que Dulcia era una mujer conflictiva, desbordante de vicio y maldad, que acostumbraba a insultar a las buenas mujeres de la calle Negrel y que, por lo tanto, no merecía vivir allí. Para probar lo anterior llamó a seis testigos cuyo testimonio fue formulario e intercambiable y de una notable falta de precisión cronológica - una característica que sugiere que quien daba el testimonio era más importante que lo que el testimonio reve-

61 ADBR 3B 4l, fols. 164r-185v, 16 de agosto de, 1340.

Hispania, LVII/3, núm. 197 (1997) 1049-1077 
laba. Tres de los testigos eran zapateros y cabezas de familia de la calle Negrel: testigos expertos, en efecto, personas que conocían los nombres de las «buenas mujeres" que habían sufrido los insultos de Dulcia y podían trazar una simple topografía del vecindario de la calle Negrel ${ }^{62}$. Utilizando el testimonio de los tres hombres, Guilhem fijo el objetivo común de todos los zapateros de la calle Negrel: echar a Dulcia. Pero aun así, esto era a todas luces insuficiente, porque producía el efecto de hacer aparecer la cuestión como una pelea privada entre zapateros. En consecuencia, Guilhem buscó tres nuevos testigos, un cristalero, una antigua doncella al servicio de Antoni y un comerciante ${ }^{63}$. La doncella, Aycelena d'Albanha, no ofreció una nueva perspectiva a pesar de su privilegiado puesto de observación, sin embargo fue claramente utilizada para demostrar con qué frecuencia incluso los que estaban al servicio de Antoni podían volverse contra él. El testimonio de los dos hombres fue aún más importante, pues ambos gozaban de cierta posición y ninguno vivía en la calle Negrel. Otras fuentes revelan que el cristalero, Peire Bermon, vivía en el barrio viejo de los cristaleros, que se hallaba al principio de la calle Negrel hacia el norte. El comerciante, llamado Jacme Bermon (no emparentado con Peire), vivía casi con toda seguridad en la calle de los Pañeros Alta, que atravesaba la calle Negrel por el sur. A través del testimonio de ambos, Guilhem de Podio pudo demostrar, de una forma muy especial, cómo las palabras sobre la conducta de Dulcia se habían difundido más allá de los límites de la calle Negrel hacia el norte y hacia el sur, llegando hasta el mundo social de los cristaleros y de los ricos comerciantes. Esta demostracion puede haber sido uno de los factores que influyeron en la decisión tomada por el juez a su favor.

En teoría, el conocimiento sobre un acontecimiento debía circular por la ciudad, como observamos en un fragmento de un tercer caso relacionado con una refriega en $1353^{64}$. La historia fue como sigue. Una mujer llamada Amelha se vio envuelta en una disputa con Aycarda Borgonha, mujer del pañero Andrieu Borgonho, a la puerta de la casa de Aycarda. La disputa terminó con la señora Aycarda insultando públicamente a Amelha, a la que llamó puta. Bernat de Conchis, que se hallaba cerca, acudió en defensa de la insultada Amelha, e inmediatamente el marido de Aycarda Andrieu, su hijo Gilon y un amigo, Lois Martin, salieron apresurados de la casa. Según un testigo de la investigación, Amelha pudo haberle dicho a Bernat de Conchis: "Sujeta a este muchacho porque quiere matarme» ${ }^{65}$, refiriéndose presumiblemente al joven Gilon; pero fue Bernat quien salió peor librado: Lois Martin le golpeó hiriéndole en la mano y en el brazo.

A los extractos de la pesquisa que permiten la reconstrucción de este relato sigue una apelación interpuesta por Andrieu, Aycarda y Gilon Borgonho con-

62 Ibid., fols. $166 r-168 \mathrm{v}$.

63 lbid. fols. $169 \mathrm{r}-17 \mathrm{lr}$.

64 ADBR 3B 50, folios sueltos localizados al final del registro.

as $\mathrm{lbid}$., testimonio de Dulsona Rauqueta, fol. Iv; «Bernardus, tene istum puerum quia valt me interficere».

Hispania, LVIL/3, núm. 197 (1997) 1049-1077 
tra los resultados de la investigación. La familia se basó en el testimonio dado por el mismo Andrieu en la pesquisa original, según el cual mientras él, Andrieu, estaba almorzando, Amelha llegó y empezó a insultar a la «gente de su casa" (verba iniuriosa dicebat... contra gentes domus sue). Andrieu le dijo: "Señora, no debería decirme esas palabras delante de mi propia casa" (domina, non dicatis ante januam meam michi verba). Pero la verdadera intención de Andrieu con este testimonio se vió claramente cuando él y su familia hubieron de presentar su propia interpretación del caso: Amelha era de hecho una vil puta. Nos enteramos de que siendo doncella (ancilla) del pañero Johan Bernat, con frecuencia fornicaba con gran cantidad de hombres. Aycarda, por el contrario, era una bona domina y Andrieu un homo pacificus.

Para nuestro propósito, las característias más importantes de este caso se encuentran, primero, en la habilidad de Andrieu para impugnar el testimonio adverso de tres testigos de la investigación --los tres vinculados por lazos de servicio y de sangre con el patrono de Amelha, Johan Bernat-y, segundo, en la naturaleza de los testigos reclutados a continuación en favor de la familia Borgonho. Éstos incluían a vecinos, a pañeros no residentes (colegas de Andrieu) y a dos personas que de ningún modo se hallaban relacionadas de manera cercana. El pañero Folco Rainos y el peletero Guilhem Benezeg eran evidentemente hombres de cierta posición, pues ambos habían sido en uno u otro momento rectores del hospital de St. Esprit. Los dos testigos distantes incluian a un notario y funcionario de la curia, Johan de Montesalino, y al calafateador Johan Isnart que vivía a varias manzanas de la casa. En resumen, la historia de Andrieu fue corroborada por una comunidad de conocimiento mucho más amplia que no sólo sobrepasaba las límites de condición social sino que se distribuía por toda la ciudad. Aunque no contamos con la resolución resultado final, el caso terminó de una forma que sugiere que la victoria fue para la familia Borgonho.

Un último caso resulta fascinante por lo que revela no sólo sobre cómo se conocía y probaba la paternidad en los tribunales, sino también sobre las distintas estrategias de nobles y plebeyos para congregar testigos distantes social y geográficamente. El 19 de febrero de 1355, el poderoso noble Laugier de Soliers acudió al palacio del juez, Pons Chays, para presentar una demanda por impago de renta en nombre de su suegra, Johanna Bonpara. Johanna era mujer del noble Olivier Bonpar e hija de Jacme Bausan ${ }^{66}$. La demanda decía que Bertran Peire, difunto, no le había pagado a Johanna nueve libras de renta adeudadas por un huerto. Un rasgo sorprendente del caso es que no se ofrecieron pruebas escritas de ninguno de los argumentos utilizados por las partes. Laugier se las arregló para congregar a cinco testigos que testimoniaron los diversos puntos que presentó.

El mejor testimonio lo proporcionó el primer testigo, el viejo noble Laurent Ricau, que se hallaba muy bien informado sobre los propietarios originales, el trabajador Guilhem Peire y su hijo Bertran. El testigo informó que el

66 ADBR 3B 58, fols. 92r-112r, 19 de febrero de 1355.

Hispania, LVIV/3, núm. 197 (1997) 1049-1077 
trabajador Guilhem había recibido la tierra como dote de su mujer, Sileta Flora. Para probar que conocía bastante a Guilhem, el testigo describió al tribunal sus rasgos físiscos: Guilhem era un hombre mayor, de estatura media, rostro honesto, y casi ciego. Cuando el tribunal le preguntó si Bertran era de hecho el hijo de Guilhem, el testigo contestó que sí, que al menos eso creía la gente (prout de eo erat publica vox et fama in civitate Massilie), pues Guilhem lo había educado y alimentado en su propia casa como hijo legitimo. Respecto a si Bertran habia nombrado de hecho a Guilhem de Montels para sucederlo, el testigo explicó que él mismo había leído el testamento escrito por el notario Peire Verdelhon en el que Bertran nombraba a Guilhem su heredero universal ${ }^{67}$. También había lédo el documento de la dote de Beatrix, la madre de Johanna, por el cual podía confirmar que la renta le pertenecía y que por supuesto ella estaba en condiciones de dejársela a su hija Johanna. Ninguno de estos documentos fue presentado ante el tribunal para su inspección por el juez. Además confesó que con frecuencia había visto a Bertran pagando la renta a Olivier Bonpar - la renta, explicó en un alarde de conocimiento íntimo, no era de hecho nueve libras, pues había sido reducida a siete libras, cuatro chelines y un penique - -y había oído incluso a Bertran pidiendo a sus trabajadores que no olvidaran coger fruta madura para Olivier y Johanna. El testigo incluso menciono el tipo de frutas entregadas: higos, peras, ciruelas, cerezas, melocotones y otras.

Al final del testimonio de Laurent, el juez, quizás prevenido por la parte contraria, preguntó por la relación existente entre Laurent y los litigantes que habian solicitado su testimonio. ¿Era pariente de Johanna? No exactamente, explicó Laurent, aunque ella era su comadre (comater sua) y la primera mujer de Laurent había sido prima carnal de Johanna.

Siguió entonces el testimonio de Jacme Bausan, quien, corno padre de Johanna, estaba en condiciones de confirmar la dote. Luego llegó el tío materno de Johanna, Bertran de Buco, que explicó que había sido él quien habia asignado la renta original en dote a su hermana Beatrix, la madre de Johanna. El siguiente testigo fue una mujer llamada Bertrana Viventa. Su testimonio fue decisivo para el caso porque todos los demás testigos se hallaban emparentados de una $u$ otra forma con Johanna y su yerno Laugier de Soliers. Bertrana explicó que Guilhem Peire habja sido su vecino tres decenios antes, y proporcionó también una breve descripción de Guilhem. También confirmó la opinión general de que Bertran era considerado hijo de Guilhem por sus conocidos (per gentes cognoscentes eosdem). Al ser preguntada cómo podía saber que Bertran pagaba la renta regularmente a Johanna, respondió que había visto entregas de cincuenta y dos chelines, cincuenta y dos chelines y cuarenta chelines y un penique, $y$, como era costumbre, él habra mencionado y llamado a varias personas para testificar las transacciones (nominabat et vocabat aliquos testes). También había visto a Johanna trayendo a la casa de Bertran dos cestas vacías para recoger la fruta en la temporada de cosecha.

${ }^{67}$ El estado legal de Guilhem de Montel - - iera legatario o heredero?- nunca fue aclarado. 
Como en el caso anterior de Laurent, el juez entonces indagó cuidadosamente sobre su condición social y su implicación con los litigantes. Preguntada si había algún tipo de enemistad con Guilhem de Montels (inimica Guilletmi de Montiliis aut inimicatus eidem), contestó que no y explicó que incluso prefería comprarle ropa a él que a cualquier otro pañero. Esta mujer, en respuesta a otras preguntas contestó que posefa una fortuna de entre sesenta y setenta libras, que tenía aproximadamente cuarenta años de edad y que no se estaba al servicio ni de Johanna ni de Laugier.

Al llegar a este punto, el caso parecía suficientemente claro: el pago de la renta había sido establecido por un uso prolongado y la vía por la que la propiedad de la renta llegó a Johanna parecía ser impecable. Al cuestionar el caso tal y como lo había expuesto Laugier, el demandado Guilhem de Montels decidió de hecho no hacerlo sobre ésto. Su único interés fue más bien impugnar el testimonio proferido contra él.

Primero, explicó que Laurent Ricau no era un espectador inocente del caso sino que de hecho había instigado el pleito y por lo tanto se le debería impedir que diese testimonio; 2 . Laurent también habła conducido a Johanna a que abriese el caso, lo que implicaba que había utilizado a Johanna como un medio para perseguir a Guilhem; 3 . Bertran de Buco había tomado partido expresamente por Johanna (partem expresse fecit) por lo que su testimonio debería ser desestimado. Añadiendo los aspectos posiblemente más desfavo. rables de todos: 4. Bertrana Viventa era una mujer de bajo nivel y mala vida, una prostituta pública; 5. había dado dos hijos a un tal Johan Jaufres; 6. además, Bertrana era, pese a negarlo en la declaración que había hecho, sirvienta de Laugier de Soliers, y comía, bebía y vivía en su casa.

Todos los testigos llamados por Guilhem sostuvieron diversos aspectos de este argumento. Para probar la implicación de Laurent en el pleito, Guilhem de Sant Gili testificó que un día, aproximadamente un año antes, había oído a Laurent Ricau discutiendo con Guilhem de Montels en el taller de éste último en la Calle Alta de los Pañeros. Esta discusión fue confirmada por el testigo Pons Columbier. El tercer testigo, Peire Martin, comentó que hacía dos o tres años que había visto a Bertrana insultando a sus vecinas en la Calle de los Pasos, y que entonces había oído como éstas la llamaban vil y prostituta ${ }^{68}$; estas mujeres también le habían dicho que tenía un hijo de Bertran Jaufres (no el Guilhem mencionado por el demandado Guilhem de Montels). Además este testigo también la había visto viviendo en la casa de Laugier. Por último, Guilhem Borme notificó que el rumor público decía que Bertrana, mientras vivió en la casa del padre de Laugier, Raymon, había tenido dos hijos de Bertran Jaufres, quien formaba parte de la guardia personal de Raymon.

Como este caso sugiere y otros confirman, era corriente entre la nobleza que el conocimiento de sus asuntos estuviese a menudo restringido a un espa-

68 Ibid., fol. 109v; «... Bertranda verba iniurosa habebat cum vicinia sua in carreria de Scalis et tunc idem testis audivit quod vicinia ipsa seu alique mulieres de ipsa vicinia nominabant vilam feminam meretricem dictam Bertrandam Viventa...». .

Hispunia, LVIU3, núm. 197 (1997) 1049-1077 
cio privado definido por sus parientes nobles o sus sirvientes. Por qué sucedía así no está muy claro. Guilhem de Montels se las ingenió para demostrar que los testigos y litigantes contrarios constituian un círculo unido por lazos de sangre, matrimonio y servicio, y que las reglas probatorias hacían que tal testimonio fuera sospechoso. Guilhem de Montels tuvo mucho más éxito reclutando a sus propios testigos. De los cuatro hombres que rindieron testimonio en su favor, uno era un notario, Pons Columbier, teóricamente público e imparcial. Guilhem de Sant Gili era un noble sin ninguna conexión clara con el hombre que solicitó su testimonio. Probablemente, era un transeúnte casual de la Calle Alta de los Pañeros cuando acertó a oír los comentarios incriminatorios intercambiados entre Laurent Ricau y Guilhem de Montels un año antes. Esto hace pensar que los comerciantes se aprovechaban de la naturaleza pública de su oficio, del constante ir y venir de gente por delante de sus talleres o sus casas. Los dos testigos restantes residían ambos en la calle en cuestión y por lo tanto vivían a cierta distancia de Guilhem de Montels. En resumen, Guilhem fue un decidido partidario de reunir testigos de un amplio espectro social y geográfico. Nuevamente, no se nos dice el resultado del caso, pero todo indica que la victoria fue de Guilhem.

En los cuatro casos expuestos antes hemos examinado la importancia que daban los litigantes a la condición social y espacial de los testigos al ver cómo intentaban reclutarlos entre diversos grupos. Un tercer factor a tener en cuenta era el género de los testigos. Cuando María Mayffrena testificó en favor de la familia Borgonho en el caso antes citado, su testimonio varió con respecto a los proporcionados por los cinco testigos de sexo masculino de manera sorprendente. Los hombres pudieron testificar sobre las reputaciones generales de los hombres y mujeres involucrados y dar su versión de los hechos disputados. Sin embargo, María fue la única testigo que pudo hablar sobre los asuntos domésticos, en particular que uno de los testigos contrario, Guilhem de Jerusalem, estaba al servicio de un pariente del otro litigante. En numerosos casos judiciales de la Marsella medieval descubrimos que hombres y mujeres tenían conocimiento de diferentes cosas. En muchas situaciones, por tanto, era importante para los litigantes establecer que los hechos de su disputa eran conocidos no sólo de manera lejana y amplia y por grupos de distinta condición social, sino también por hombres y mujeres.

Para empezar, casi todos los casos relacionados con un nacimiento o muerte en la Marsella de mediados del siglo XIV se apoyaba en el testimonio de una o más mujeres. Por mencionar un ejemplo, en 1348 un hombre llamado Jacme de Podio trató de reclamar los bienes de su nuera Ugueta, la última esposa de su hijo Peire, ambos muertos durante la peste sin dejar testamento ${ }^{69}$. Para fundamentar su reclamación, necesitaba comprobar que Ugueta habia muerto antes que Bilona, la hija de la pareja, pues si esto había sido así Bilona sería la heredera abintestada de Ugueta. A su vez, Peire sería el heredero de los bienes de su mujer por su hija Bilona, y el propio Jacme lo

69 ADBR 355E 292, fols. $48 \mathrm{r}+50 \mathrm{v}$, 10 de abril de 1348.

Hixpania, LVI1/3, núm. 197 (1997) 1049-1077 
sería de su hijo Peire. Según Jacme, Ugueta murió en torno a Lent. Bilona sobrevivió a su madre quince días y su padre Peire vivió apenas dos días más. Los tres testigos del orden cronológico de las muertes eran todas mujeres; primero, Ugueta Sperneria, esposa de Antoni Spernier, que afirmaba conocer la secuencia correcta de las muertes porque era vecina. En apariencia, Ugueta informó de las noticias a su vecina Johaneta Bermunda, la siguiente testigo, que testificó que había visto a Bilona caminando arriba y abajo por la calle después de la muerte de su madre. Después testificó Sanxieta de Galbert, que había visto cómo llevaban el cádaver de Bilona al cementerio, más tarde oyó la noticia de la muerte de Peire.

Un caso de octubre de 1339 muestra que las mujeres de la vecindad eran las que con frecuencia mejor llevaban la cuenta de las edades ${ }^{70}$. El caso enfrentaba a Adhemar Gamel con su hermana viuda, Pellegrina, en un pleito sobre la herencia de su madre Guilelma ${ }^{71}$. La madre había muerto hacía dieciséis años, aproximadamente en el año 1326. En su testamento, donó unos pocos bienes (principalmente ropas, pero también una cama y otras pocas enseres) a su hija Pellegrina, casada y enviudada, y también alguna cosa a Jaumeta, la hija de Pellegrina. Adhemar fue heredero de Guilelma. Pellegrina reclamó que nunca había recibido su legado. Adhemar por su parte replicó que en el momento del fallecimiento de su madre, el tenía menos de veinticuatro años de edad y carecía de tutor por lo que su hermana mayor, Pellegrina, se había encargado como tal de los bienes y, con ese poder, había tomado también todo su legado tranquilamente. Pellegrina negó haber cogido esos bienes. El caso se resolvió estableciendo la edad de Adhemar en el momento del fallecimiento de su madre.

El primer testigo, una vecina llamada Sicilia Desderia, explicó al tribunal que aunque no sabía cuando había sido nombrado heredero, lo que sí sabía era que había tenido un hijo, Guilhem, en la misma época en que Adhemar y otro muchacho vecino, Peire Rosthan, vinieron al mundo: los tres muchachos habían nacido en un espacio de dos meses entre el primero y el último. Sabía esto porque las otras dos mujeres vivian en la misma calle (nam ipsa testis et Guillelma Gamella et Berengaria Rostagna mater dicti Petri Rostagni una carreria morabantur). Su hijo tenía ahora treinta y ocho años de edad, lo que significaba que Adhemar tenfa veintidós en el momento en que fue hecho el testamento.

El segundo y tercer testigos, respectivamente, la esposa de Adhemar, Jacma, y otro vecino, el calafateador Johan Barratan, testimoniaron entonces sobre lo ocurrido a la muerte de la madre diciendo que Pellegrina habia cogido realmente la cama y otros objetos. Johan, al escuchar la noticia de la muerte de Guilelma, llegó junto con otros vecinos para velarla, lo que le pro-

70 Esto era de particular importancia en el derecho romano, en el cual el estado legal dependia parcialmente de la edad. Véase Thomas Kuehn, Emancipation in Late Medieval Florence. New Brunswick, N J, 1982.

71 ADBR 3B 38, fols. 63r-66v, 14 de octubre de 1339. 
porcionó una visión privilegiada de las sucesos en la casa y permitía que pudiera reconocer las cosas, en particular la cama, que Pellegrina poseía ahora. A pesar de ser antiguos vecinos, no testimonio sobre la cuestión de la edad de Adhemar. El cuarto testigo, Berengiera Rostahna, volvió sobre este asunto y esencialmente prestó el mismo testimonio que Sicilia Desderia. El último que llegó fue el mismo Peire Rostahn, contemporáneo de Adhemar, aunque no se le preguntó por su edad.

Las mujeres entraban con frecuencia en las casas de sus vecinas para charlar y compartir la comida y, en general, tenían más oportunidades que los hombres de observar las posesiones de la casa. Un caso excelente que contiene gran cantidad de cuestiones relevantes puede verse en una disputa por herencia en junio de 1353, que enfrentó a Jacma, viuda del difunto trabajador Peire Bernis, con el heredero de Bernis, Bernat Raymbaut ${ }^{72}$. Sabemos por la narración que la demanda de Bernat consistía en lo siguiente: aunque el difunto Peire había dejado a su viuda Jacma un legado de sesenta libras, ella había cogido violentamente gran cantidad de cosas (todos enumeradas) de la casa de Peire, artículos que valían mucho más que las sesenta libras. Jacma contestó lo siguiente: 1 . que la casa, situada en la calle de los Curtidores, donde la pareja había vivido no era de Peire, sino que de hecho pertenecía a su dote; 2. que muchas de las cosas de la lista de Bernat llegaron con la dote (esto implica que se hallaban en la casa en el tiempo del matrimonio); 3. que Peire le había dejado no sólo sesenta libras sino todo lo demás que pertenecía a la casa en cuestión (arnesia ac totum froirum quae et quod erant infra dictam domum ... dotalem); 4. que después de fallecer Peire, el propio Bertran había cogido violentamente varias cosas pertenecientes a Jacma; 5 . que todo esto era conocido por sus vecinos.

El testimonio indica que Peire murió durante la peste y que la disputa surgió, al menos en parte, por las incertidumbres sobre la posesión provocadas por la epidemia. También parece que Bertran, como heredero, había recibido de hecho muy poco por via hereditaria, y su rabia parece derivada de la creencia equivocada de que la dote de una mujer pertenecía al marido de ésta y, en consecuencia, a sus herederos. En la propia defensa de su dote, Jacma dijo que llamaría a cuatro testigos, dos hombres y dos mujeres, aunque en realidad sólo las dos mujeres testificaron al final. Una de ellas dijo que algunas cosas de la dote, escritas en la lista, habían pertenecido originalmente a la madre de Jacma, Bernissa, y que las había visto en la casa durante al menos doce años. Sobre el tercer punto, la testigo, Jacma Colrada, refirió que ella, junto con muchos otros, había estado en la casa cuando Peire dictó su testamento y había escuchado los legados hechos a Jacma. El otro testigo, Ermelina Barreria, proporcionó un testimonio similar.

Cuando le llegó el turno, Bernat fue increiblemente incapaz de citar a algún testigo convincente. Sus tres testigos eran hombres. Gran parte del testimonio de los tres consistió en nichil scire (no saber nada), y un testigo, Ray-

72 ADBR 3B 816, fols. 12r-67v, 17 de junio de 1353.

Hispania. LVII/3, nu̇m. 197 (1997) 1049-1077 
mon Pascal, parece que incluso apoyó el derecho de Jacma. Bernat cambió de táctica, tratando de impugnar a los testigos de Jacma, diciendo que Jacma Colrada era sirvienta de Jacma Bernissa, vivía en su casa y comía, bebía y charlaba con ella, además de poseer menos de los veinte chelines necesarios para ser testigo. Llamó a una mujer para testificar lo anterior, quien contestó nichil scire a los tres puntos.

Estos ejemplos de los tipos de conocimiento femenino muestran que las mujeres controlaban formas específicas de socialización y eran depositarias de información ofda y visual. Lo que, en cierta medida, dotaba a las mujeres de un grado de poder en sus respectiva vecindad, poder del que no disponían en el espacio más amplio de la ciudad, aunque el hecho de que los hombres pudiesen testificar y lo hiciesen sobre temas similares limite la extensión de este poder. En cualquier caso, parece probable que no muchos hombres o mujeres pudiesen permitirse tener como enemigas a mujeres significativas de la vecindad y esperar obtener además apoyo firme en un pleito legal.

Estos temas destacan en un caso de 1339 que opuso a Johan Girman y a su sobrino Esteve Girman contra Jacma Thomasia por una deuda de siete libras, doce chelines y dos peniques contraida por una compra de vino ${ }^{73}$. En el momento de la apertura de la información, Esteve se hallaba en prisión a instancias de Jacma, y Johan estaba intentando sacarlo y entablar juicio contra Jacma por no haberle pagado la deuda. Según Johan, Jacma se había quejado en la investigación de que Esteve injustamente la había vejado por causa de la deuda. Johan trató de probar: 1. que Jacma era una tabernera; 2 . que Ugueta Segueria, la testigo que testimonió contra Esteve, tenía menos de doce años de edad ( $\mathrm{y}$ por tanto era demasiado joven para hacerlo); 3. que Ugueta era asimismo sobrina de Jacma; 4. que Esteve y Johan eran hombres de buena reputación que no solían mentir y solicitar a otros el pago de deudas no debidas (Stephanus et Johannes sunt homines bone fame et bone opinionis veraces et que consueverunt abstinere a querendo sibi alienum indebite et a dicendis mendacia); 5. que lo anterior era de público conocimiento en Marsella, en especial entre conocidos y vecinos (et maxime inter notos et vicinos). En los puntos uno, cuatro y cinco, Johan aportó tres testigos masculinos, todos los cuales proporcionaron entusiastas informes sobre la buena reputación de Esteve y Johan, y poco más ${ }^{74}$.

En respuesta, Jacma reunió sus armas. En dos puntos sustanciales simplemente argumentó: 1. que había pagado la deuda quince días antes en el portal de su casa; 2 . que era una mujer honesta y respetuosa de la ley, de buena posición y vida, y así la consideraban sus conocidos y vecinos. En su favor convocó a tres testigos femeninas que confirmaron de manera firme que la deuda habia sido liquidada en su presencia. A juzgar por su testimonio, Jacma, como tabernera, gozaba de una particular buena posición para reclu-

\footnotetext{
${ }^{73}$ ADBR 3B 37, fols. 264r-269r, junio de 1339.

${ }^{4}$ Jacma no respondió al segundo y tercer punto, aunque set̃aló que Ugueta era de hecho sobrina de su marido, y no suya.

Hispania, LVI/3, nüm. 197 (1997) 1049-1077
} 
tar testigos de pequeñas transacciones, porque al menos dos de estas hablan estado haciendo cola para comprar vino a Jacma cuando el finiquito tuvo lugar. El juez preguntó con cautela a cada una cuánto poseran y, a dos de ellas, si eran sirvientas de Jacma y compartían pan y vino con ella. Las dos dijeron que no. Una de ellas, Ugueta Segueria, de catorce años de edad, dijo que no sabía cuánto posela porque tenía madre y un hermano. La segunda, Bertomieua Aonna, cuando se le preguntó por su fortuna, dijo que se hallaba satisfecha con su situación y posefa una casa, aunque ignoraba su valor.

Puesto que no hubo recibo escrito del pago de la deuda, se trataba de una cuestión de la palabra de Jacma contra la de los Girman. Ambas partes tenían testigos sobre su buena posición. La notable diferencia en el testimonio, principalmente en el hecho de que Jacma pudiese convocar a testigos que vieron la transacción, procede del hecho de que ésta tuvo lugar en su espacio, en la puerta de su taberna. Y dado que los clientes de Jacma parecen haber sido predominantemente mujeres, el espacio era un espacio femenino.

El áltimo caso muestra que un grupo de testigos totalmente femenino podía poseer considerable autoridad. Otros casos revelan que aparentemente era una buena estrategia para los litigantes incluir tanto a hombres como a mujeres en el grupo de testigos que reclutaban, y la incapacidad de Esteve y Johan Girman para probar que el conocimiento de la deuda circuló entre las mujeres de la vecindad se convirtió claramente en un serio obstáculo para su caso. Al igual que la geografía y la condición social, el género era uno de los factores que los litigantes tenian en cuenta en la presentación de testigos. Por supuesto, es difícil valorar el grado de consciencia que los litigantes tenían de esta necesidad. Como se dijo antes, la práctica deliberada de la publicidad indica que en general los litigantes tenían una considerable experiencia legal. Los datos analizados muestran, por otra parte, lo normal que era que los grupos con información fuesen diversificados; esto sólo, indica un cierto grado de adaptación consciente. La diversidad en los grupos de testigos llamaba la atención de los jueces y de igual modo de los ciudadanos comunes. La evidencia más reveladora de esta exigencia quizás provenga de un testigo llamado a declarar acerca de un dominio noble. El testigo informó que cierto hecho -que el viguier era corrupto y había sido comprado por una de las partes implicadas- era tan ampliamente conocido que lo comentaban tanto judíos como cristianos (tam per judeos quam per christianos) ${ }^{75}$.

Los argumentos aquí propuestos indican que debemos considerar seriamente la cláusula de fama con que terminaban la mayoría de las informaciones de testigos de la Marsella de mediados del siglo XIV. Al presentar sus casos, los litigantes finalizaban habitualmente con una serie de puntos que eran ratificados con alguna variante de la frase "Que todo lo anterior es de voz y conocimiento público" (quod de predictis est publica vox et fama). Como proclamaba una tabernera llamada Bertomieua de Gordavilla, los hechos de su disputa eran de voz y conocimiento públicos «entre conocidos y vecinos de

75 ADBR 3B 820, fol. 70v, 7 de julio de 1356.

Hispania, LVIJ/3, núm. 197 (1997) 1049-1077 
la mencionada Bertomieua y aquellos que la han conocido durante largo tiempo" ${ }^{76}$. Un comerciante llamado Peire de Brandis alegaba que sus actos eran conocidos no sólo en Marsella sino en diversos lugares de toda la Provenza ${ }^{7}$. Los jueces podían interrogar a los testigos sobre este particular y lo hacían. Hemos oído la respuesta dada por Johan Senequier: fama es "lo públicamente hablado por la gente». Otro testigo informó que fama «es lo que es comentado por muchos y nunca se ha oído a nadie decir lo contrarion ${ }^{78}$. La cláusula de fama prentendía afirmar de modo explícito lo que los litigantes implícitamente trataban de demostrar al reclutar grupos de testigos socialmente diversos.

\section{CONCLUSIÓN}

El testimonio de testigos es notoriamente poco fiable y opera sin mencionar que los testigos reclutados por litigantes contrarios cuentan habitualmente historias muy distintas. A veces las historias caen bajo el peso de sus propias incoherencias, dando, por consiguiente, la victoria del caso a la parte contraria. En otras ocasiones, jueces y jurados, en su esfuerzo para averiguar la verdad, no pueden apoyarse en la evidencia interna. En la actualidad, existe una gran variedad de estrategias a disposición de los tribunales para autentificar o deslegitimar las reclamaciones presentadas por los litigantes: evidencia circunstancial, pruebas con detectores de mentiras, testigos expertos. Estas estrategias tienen la doble virtud de ser, o parecer, neutrales y expertas. No se disponía de ellas en la Marsella bajomedieval. En consecuencia, los tribunales de justicia hallaban medios independientes de corroboracion mediante el examen de la naturaleza del grupo informado. Por lo menos, muchos litigantes asumian que los jueces analizarian el perfil social de sus testigos y, para acomodarse a este hecho, reclutaban de manera consciente grupos de testigos diversificados.

Los grupos que informan convencen a los jueces cuando llevan la impronta de la variedad. Esta es una actitud que surge en la Marsella medieval de la expectativa de que el conocimiento mismo es un asunto de registro público, conocido en todas partes, siempre y por todos. Debía ser conocido por gentes cercanas y por extraños, por plebeyos y nobles, por compañeros artesanos y profesionales del derecho, por hombres y mujeres. El conocimiento adquirirá esta cualidad siempre que los actos sean realizados públicamente, siempre que los notarios hagan los contratos públicos, siempre que los vecinos vean llaves en las manos de sus vecinos cabezas de familia, siempre que los hombres y las mujeres anuncien las muertes de la parentela. En particular, el conocimiento deriva su autoridad, su facultad de ser cierto y vinculante

\footnotetext{
${ }^{76}$ ADBR 3B 34, fol. 19r, 24 de abril de 1338.

77 ADBR 3B 811, fol. 159r, 11 de febrero de 1352 .

78 ADBR 3B 37, fol. 265v, junio de 1339.
} 
legalmente, cuando se ajusta a los preceptos de la versión de la fórmula vicentina del siglo XIV.

Como conclusión, merece la pena hacer una mención a la naturaleza del conocimiento inscrito, por actos públicos, en las memorias del público general. Hemos visto ejemplos de hechos relacionados con el nacimiento, la muerte, la situación marital, el parentesco, el título y la propiedad. Los archivos notariales del siglo XIV, aunque enormes y creciendo a pasos agigantados cada decenio, se relacionaban principalmente con deudas; por lo general no registraban otro tipo de información, y por lo tanto no crearon un archivo escrito de conocimiento en lo relativo a hechos que con frecuencia eran motivo de disputa. Estos hechos se almacenaron en los archivos de la memoria, y era la conducta pública lo que los registraba allí. Podemos sostener que las exigencias de los tribunales basados en el Derecho Romano de este tipo de actos incrementaron la presión sobre los archivos de conocimiento y estimularon a practicar el tipo de comportamientos estudiados en este artículo.

Sin embargo, durante los siglos siguientes, estos actos se convertirían en información escrita y pasarían a los archivos estatales y a los registros parroquiales. EI proceso se completó en numerosos Estados europeos en el siglo XIX. Por supuesto, esta transformación que experimentan los archivos de conocimiento difícilmente eliminó las disputas, ya que se puede disputar con la misma facilidad sobre hechos escritos, y tampoco los conflictos por cuestiones de honor y jerarquia han disminuido sustancialmente en el mundo moderno. Pero estas transformaciones en la práctica de registar tuvieron profundos efectos en la sociedad, puesto que eliminaron una de las razones fundamentales de la cultura medieval de la publicidad, principalmente el requisito legal de crear recuerdos. No es preciso mostrarse romántico con un mundo perdido para observar que, con este cambio, las personas dejaron de estar implicadas legalmente en la publicidad de un nacimiento o la muerte a un vecino. Ya no fue preciso casarse a la vista del público. Se podían comprar $y$ vender propiedades en la privacidad del despacho de un abogado sin tener en cuenta a los vecinos ni sus deseos de conocer. Resumiendo, este cambio en los archivos hizo posible la reclusión del conocimiento, lo que permitió que muchas formas de conocimiento se volviesen objetos manipulables por un Estado y por una casta cerrada de burocratas y expertos legales, y no por la opinión común de hombres y mujeres corrientes ${ }^{79}$.

Traducido por Jesús Izquierdo Martín Universidad Autónoma de Madrid

79 El proceso aquí descrito tiene cierto paralelismo con los argumentos de Jürgen Habermas, aunque Habermas discutía una clase distinta de conocimiento. Véase su Strukturwandel der Offentlichkeit: Untersuchungen zu einer Kategorie der bürgerlichen Gesellschaft. Berlín, 1962.

Hispania, LVIt/3, núm. 197 (1997) 1049-1077 